\title{
Comparison of the Extractabilities of Tetrachloro- and Tetrabromo- palladate(II) Ions with a Thiodiglycolamide Compound
}

\author{
Hirokazu Narita, ${ }^{* \dagger}$ Motoki Maeda, ${ }^{* * *}$ Chiharu Tokoro, ${ }^{* *}$ Tomoya Suzuki, ${ }^{*}$ Mikiya TanaKa,* \\ Ryuhei MOTOKAWA, ${ }^{* * *}$ Hideaki ShIWAKU, ${ }^{* * * *}$ and Tsuyoshi YaITA $* * * *$ \\ *Environmental Management Research Institute, National Institute of Advanced Industrial Science and \\ Technology (AIST), 16-1 Onogawa, Tsukuba, Ibaraki 305-8569, Japan \\ **Department of Earth Science, Resources and Environmental Engineering, Faculty of Creative Science and \\ Engineering, Waseda University, 3-4-1 Okubo, Shinjuku, Tokyo 169-8555, Japan \\ ***Materials Sciences Research Center, Japan Atomic Energy Agency (JAEA), 1-1-1 Koto, Sayo, Hyogo 679-5148, \\ Japan
}

\begin{abstract}
Using $N, N, N^{\prime}, N^{\prime}$-tetra-2-ethylhexyl-thiodiglycolamide (TEHTDGA) in $n$-dodecane as the extractant, we compared the percentages of $\mathrm{Pd}(\mathrm{II})$ extracted from $\mathrm{HCl}$ and $\mathrm{HBr}$ solutions, and analyzed the structures of the $\mathrm{Pd}(\mathrm{II})$-extractant complexes. For comparison, similar experiments were performed with di- $n$-hexyl sulfide (DHS), a well-known sulfide-type extractant. TEHTDGA extracted Pd(II) from both $\mathrm{HCl}$ and $\mathrm{HBr}$ solutions much faster than DHS. The Pd(II)/(TEHTDGA or DHS) stoichiometry in the organic phase was 1:2. For TEHTDGA, the extractability of Pd(II) from $\mathrm{HBr}$ solution was inferior to that from $\mathrm{HCl}$ solution, whereas the opposite was true for DHS. However, FT-IR spectroscopy and EXAFS measurements indicated that the inner-sphere structure of Pd(II) in the TEHTDGA complex was almost the same as that in the DHS system: in both cases, two of the halide ions in the tetrachloro- or tetrabromopalladate(II) ion were replaced by the sulfur atoms of two extractant molecules.
\end{abstract}

Keywords Palladium, $\mathrm{HCl}, \mathrm{HBr}$, liquid-liquid extraction, thiodiglycolamide

(Received June 27, 2017; Accepted August 9, 2017; Published November 10, 2017)

\section{Introduction}

The need to separate and purify platinum group metals (PGMs) from acidic chloride media often arises during mining and recycling processes because of the common use of $\mathrm{HCl}$ solutions with the addition of $\mathrm{Cl}_{2}$ gas during PGM leaching. ${ }^{1}$ Therefore, the liquid-liquid extraction of PGMs from $\mathrm{HCl}$ solutions has been extensively studied. In addition, PGM extraction from $\mathrm{HNO}_{3}$ solutions has also been studied for the removal of PGMs from high-level liquid wastes generated by nuclear fuel reprocessing. ${ }^{2}$ In contrast, there have been few studies of PGM extraction from acidic bromide media. ${ }^{3-9}$ The replacement of chloride ions by bromide ions in PGM complexes frequently enhances the extractability, and this phenomenon has been explained by the fact that bromo-PGM complexes are more hydrophobic than the corresponding chloro-PGM complexes. ${ }^{5,6}$

Because tetrachloropalladate(II), $\left[\mathrm{PdCl}_{4}\right]^{2-}$, is substantially more extractable than other PGM ions, ${ }^{1} \mathrm{Pd}(\mathrm{II})$ can be extracted in two different modes: via the formation of a coordination complex or via the formation of an ion-pair complex. The former generally occurs in sulfide-type extractant systems, and the latter often occurs when N-donor extractants are used. Both extraction modes have also been observed for tetrabromopalladate(II), $\left[\mathrm{PdBr}_{4}\right]^{2-} ;$ di- $n$-octyl sulfide (DOS)

$\dagger$ To whom correspondence should be addressed.

E-mail: hirokazu-narita@aist.go.jp extracts $\mathrm{Pd}(\mathrm{II})$ from $\mathrm{HBr}$ solution via a coordinative complex, ${ }^{7}$ whereas extraction by tri-i-octylamine ${ }^{8}$ and quaternary ammonium compounds ${ }^{9}$ involves the formation of an ion-pair complex (anion-exchange extraction). In these systems, $\left[\mathrm{PdBr}_{4}\right]^{2-}$ ions are extracted much more readily than $\left[\mathrm{PdCl}_{4}\right]^{2-}$ ions.

We have already found that thiodiglycolamide (TDGA) compounds are promising, practical alternatives to dialkyl sulfide compounds, such as DOS, di- $n$-hexyl sulfide (DHS), which are among the most commonly used Pd(II) extractants. ${ }^{10,11}$ TDGA compounds show good Pd(II) extraction ability and high oxidation resistance, but the mechanisms by which they extract $\left[\mathrm{PdCl}_{4}\right]^{2-}$ and $\left[\mathrm{PdBr}_{4}\right]^{2-}$ have not yet been clarified. In this study,

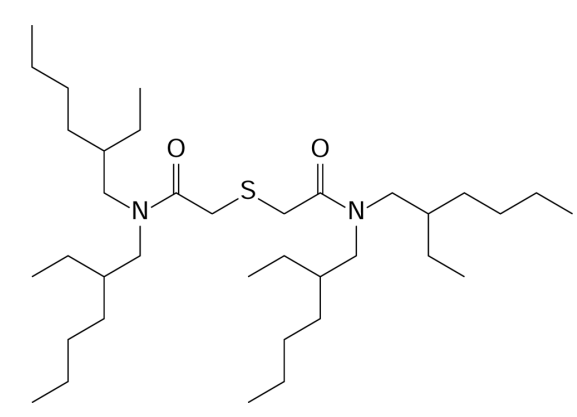

Fig. 1 Structure of $N, N, N^{\prime}, N^{\prime}$-tetra-2-ethylhexyl-thiodiglycolamide. 
we investigated the use of $N, N, N^{\prime}, N^{\prime}$-tetra-2-ethylhexylthiodiglycolamide (TEHTDGA) in $n$-dodecane to extract $\mathrm{Pd}(\mathrm{II})$ from $\mathrm{HCl}$ and $\mathrm{HBr}$ solutions (Fig. 1), and determined the structural properties of the $\mathrm{Pd}(\mathrm{II})$ complexes extracted with TEHTDGA. For comparison, we also carried out similar analyses using DHS, a well-known sulfide-type extractant.

\section{Experimental}

\section{Reagents}

TEHTDGA ( $>99 \%$ purity) and DHS ( $>99 \%$ purity) were purchased from Chemicrea (Tokyo, Japan) and Wako Pure Chemical Industries (Osaka, Japan), respectively, and were used as supplied. Aqueous solutions of $\mathrm{Pd}(\mathrm{II})$ were prepared by dissolving $\mathrm{PdCl}_{2}$ (Wako Pure Chemical Industries) and $\mathrm{PdBr}_{2}$ (Tokyo Chemical Industry Co., Tokyo, Japan) in $\mathrm{HCl}$ and $\mathrm{HBr}$ solutions, respectively. All other chemicals were of reagent grade.

\section{Extraction procedure}

A solution of TEHTDGA or DHS at various concentrations in $n$-dodecane was pre-equilibrated with a solution of $\mathrm{HCl}$ or $\mathrm{HBr}$ at various concentrations containing no $\mathrm{Pd}(\mathrm{II})$; specifically, the mixture of organic and aqueous solutions was vertically shaken at an amplitude of $100 \mathrm{~mm}$ and a frequency of 200 strokes/min in a $10 \mathrm{~mL}$ glass tube for $30 \mathrm{~min}$, and then centrifuged. A $1-\mathrm{mL}$ aliquot of the pre-equilibrated organic phase and the same volume of an $\mathrm{HCl}$ solution containing $\sim 5 \times 10^{-4} \mathrm{M} \mathrm{Pd}(\mathrm{II})\left(10^{-3}\right.$ to $10^{-2} \mathrm{M}$ for the loading capacity test) were similarly shaken for various durations, and then centrifuged. All of the operations were carried out at room temperature $\left(23 \pm 2^{\circ} \mathrm{C}\right)$. Extraction of the acids was evaluated on the basis of the difference between the $\mathrm{H}^{+}$concentrations in the initial aqueous phase and the equilibrated aqueous phases, as measured by titration with $\mathrm{NaOH}$. The concentrations of metal ions in the aqueous phase were measured by means of ICP-AES (Horiba ULTIMA2). The extraction percentages $(E \%)$ were determined by means of the following equation: $E \%=\{([\mathrm{Pd}(\mathrm{II})]$ in the initial aqueous phase $)-([\operatorname{Pd}(\mathrm{II})]$ in the equilibrated aqueous phase $)\} /([\mathrm{Pd}(\mathrm{II})]$ in the initial aqueous phase). The $E \%$ values for $\mathrm{Pd}(\mathrm{II})$ were measured in triplicate. The error in the $E \%$ values was estimated to be $<5 \%$.

\section{FT-IR spectroscopy}

Five types of organic samples were prepared for FT-IR spectroscopy: (i) $0.50 \mathrm{M}$ TEHTDGA in $n$-dodecane, (ii) $0.50 \mathrm{M}$ TEHTDGA in $n$-dodecane pre-equilibrated with $1.0 \mathrm{M} \mathrm{HCl}$, (iii) $0.50 \mathrm{M}$ TEHTDGA in $n$-dodecane pre-equilibrated with 1.0 M HBr, (iv) a Pd(II) complex sample obtained by using solution (ii) to extract a solution of $0.30 \mathrm{M} \mathrm{PdCl}_{2}$ in $1.0 \mathrm{M} \mathrm{HCl}$, and (v) a Pd(II) complex sample obtained by using solution (iii) to extract a solution of $0.30 \mathrm{M} \mathrm{PdBr}_{2}$ in $1.0 \mathrm{M} \mathrm{HBr}$. Samples (ii) - (v) were prepared by means of the extraction procedure described above, with a shaking time of $120 \mathrm{~min}$. The concentration of Pd(II) in samples (iv) and (v) was $0.25 \mathrm{M}$. Each of the five organic samples was placed in a diamond compression cell (Systems Engineering). FT-IR spectra were collected with a PerkinElmer Spectrum 100 instrument.

\section{EXAFS measurements}

The following four samples were prepared for EXAFS measurements: $0.10 \mathrm{M} \mathrm{Pd}(\mathrm{II})$ in $1.0 \mathrm{M} \mathrm{HCl}$ (designated CL$\mathrm{Aq}), 0.10 \mathrm{M} \mathrm{Pd}(\mathrm{II})$ in $1.0 \mathrm{M} \mathrm{HBr}$ (BR-Aq), a $0.10 \mathrm{M} \mathrm{Pd(II)}$ sample obtained by extraction of a solution of $0.10 \mathrm{M} \mathrm{PdCl}_{2}$ in

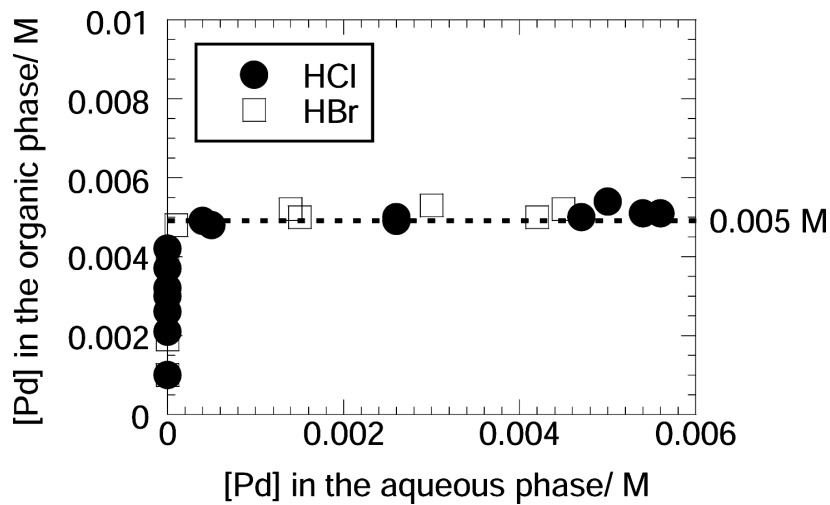

Fig. 2 Relationship between the Pd(II) concentrations in equilibrated organic and aqueous phases. [TEHTDGA] $=0.010 \mathrm{M},[\mathrm{HCl}, \mathrm{HBr}]=$ 1.0 M, shaking time $=90 \mathrm{~min}$.

1.0 $\mathrm{M} \mathrm{HCl}$ with $0.50 \mathrm{M}$ TEHTDGA in $n$-dodecane (CL-Ex), and a $0.10 \mathrm{M} \mathrm{Pd}(\mathrm{II})$ sample obtained by extraction of $0.10 \mathrm{M}$ $\mathrm{PdBr}_{2}$ in $1.0 \mathrm{M} \mathrm{HBr}$ with $0.50 \mathrm{M}$ TEHTDGA in $n$-dodecane (BR-Ex). The CL-Ex and BR-Ex samples were prepared by means of the extraction procedure described above. Samples with DHS were prepared in a similar manner.

The EXAFS measurements were performed on BL11XU at SPring- 8 by a method similar to that described previously. ${ }^{12}$ As model compounds for the FEFF calculations, we used the reported crystal structures of $\left[\mathrm{PdCl}_{4}\right]^{2-},{ }^{13}\left[\mathrm{PdBr}_{4}\right]^{2-},{ }^{14}$ and a dichloro-bis( $p$-t-butylphenylbutyl sulfide) Pd(II) complex. ${ }^{15}$ For the complex between the sulfide-containing ligand and palladium bromide, we used a hypothetical structure in which two $\mathrm{Br}$ ions in the $\left[\mathrm{PdBr}_{4}\right]^{2-}$ complex were replaced by two sulfur atoms. Multiple scattering paths were ignored because their contribution was not significant in the studied systems.

\section{Results and Discussion}

\section{Effect of the shaking time on the extraction percentage}

Analysis of the effect of the shaking time on the percentage of $\mathrm{Pd}(\mathrm{II})$ extracted from $1.0 \mathrm{M} \mathrm{HCl}$ or $\mathrm{HBr}$ with $0.010 \mathrm{M}$ TEHTDGA revealed that approximately $100 \%$ of the $\mathrm{Pd}(\mathrm{II})$ was extracted from both $\mathrm{HCl}$ and $\mathrm{HBr}$ solutions in $<5 \mathrm{~min}$. In contrast, when 0.010 M DHS was used, $\sim 20$ and $\sim 90$ min were required to achieve nearly $100 \% \mathrm{Pd}(\mathrm{II})$ extraction from $\mathrm{HBr}$ and $\mathrm{HCl}$, respectively (Fig. S1, Supporting Information). It has already been reported that $\mathrm{Pd}(\mathrm{II})$ extraction in the TDGA-HCl system is faster than that in the DHS-HCl system. ${ }^{10,11}$ In this study, we found that $\mathrm{Pd}(\mathrm{II})$ in a $\mathrm{HBr}$ solution was also extracted rapidly with TDGA.

\section{Estimated Pd(II)/TEHTDGA stoichiometry}

We estimated the Pd(II)/TEHTDGA stoichiometry of the complex extracted into the organic phase by measuring the Pd(II) loading capacity. Figure 2 shows the relationship between the equilibrated $\mathrm{Pd}(\mathrm{II})$ concentrations in the organic and aqueous phases for extraction conditions of $0.010 \mathrm{M}$ TEHTDGA and $1.0 \mathrm{M} \mathrm{HCl}$ or $\mathrm{HBr}$. The profile for extraction from $\mathrm{HCl}$ was the same as that for extraction from $\mathrm{HBr}$. The $\mathrm{Pd}(\mathrm{II})$ concentration at saturation was approximately $0.005 \mathrm{M}$, indicating that a 1:2 Pd(II)/TEHTDGA complex predominated in both systems. The same stoichiometry was observed in the DHS system (Fig. S2, Supporting Information). 


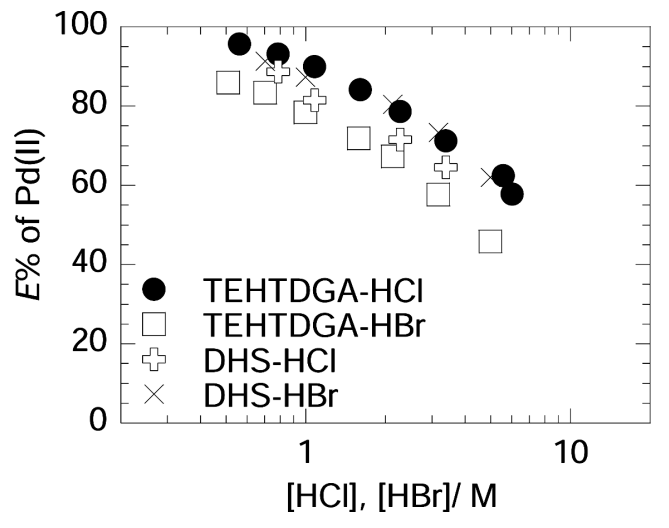

Fig. 3 Relationship between the Pd(II) extraction percentage (E\%) and the $\mathrm{HCl}$ and $\mathrm{HBr}$ concentrations. [TEHTDGA] $=0.0010 \mathrm{M}$, shaking time $=90 \mathrm{~min}$.

Effects of the $\mathrm{HCl}$ and $\mathrm{HBr}$ concentrations on the extraction percentage

We began by investigating the extraction of $\mathrm{HCl}$ and $\mathrm{HBr}$ with $0.50 \mathrm{M}$ TEHTDGA or DHS at acid concentrations ranging from 0.50 to $6.0 \mathrm{M}$. We found that extraction of the acids into the organic phase was negligible under the condition of $\leq 0.50 \mathrm{M}$ TEHTDGA or DHS.

When we plotted the $E \%$ values for the extraction of $\mathrm{Pd}(\mathrm{II})$ with $0.0010 \mathrm{M}$ TEHTDGA or DHS as a function of the $\mathrm{HCl}$ and $\mathrm{HBr}$ concentrations (Fig. 3), we found that $E \%$ decreased with increasing the $\mathrm{HCl}$ and $\mathrm{HBr}$ concentrations in both extractant systems. In the case of $\mathrm{Pd}(\mathrm{II})$ extraction via the formation of an ion-pair complex (anion-exchange extraction), a competitive reaction of a metal anion and counter ions can decrease $E \%$. However, neither TEHTDGA nor DHS extracted $\mathrm{HCl}$ or $\mathrm{HBr}$ (that is, no protonation reaction occurred). Considering that the anionic complexes (i.e., $\left[\mathrm{PdCl}_{4}\right]^{2-}$ and $\left[\mathrm{PdBr}_{4}\right]^{2-}$ ) predominated under our extraction conditions (as will be mentioned later), the decrease in $E \%$ with increasing acid concentration was probably caused by the replacement of two of the $\mathrm{Cl}^{-}$or $\mathrm{Br}^{-}$ions with two extractant molecules:

$$
\begin{aligned}
{\left[\mathrm{PdX}_{4}\right]^{2-}+2 \mathrm{E} \underset{(\mathrm{X}=\mathrm{Cl} \text { or } \mathrm{Br}, \mathrm{E}=\mathrm{TEHTDGA} \text { or DHS })}{\rightleftharpoons} }
\end{aligned}
$$

Interestingly, in the TEHTDGA system, the $E \%$ values for $\mathrm{HCl}$ were higher than those for $\mathrm{HBr}$; this contrasts with the results in the DHS system and the previously reported DOS system. ${ }^{7}$ To explore the reason for the difference between these results, we analyzed the structures of the Pd(II) complexes in the organic phase.

\section{Properties of the amide oxygen atom}

To clarify the role of the amide oxygen atoms in the TEHTDGA molecule, we compared the frequencies of the carbonyl stretching vibration at around $1645 \mathrm{~cm}^{-1}$ in the FT-IR spectra of organic solutions of TEHTDGA before and after equilibration with $1.0 \mathrm{M} \mathrm{HCl}$ or $\mathrm{HBr}$ solution in the absence and presence of Pd(II) (Fig. 4). The spectra of the equilibrated solutions showed almost the same shape and position as the spectrum of the free TEHTDGA solution. This result is consistent with our observation that neither $\mathrm{HCl}$ nor $\mathrm{HBr}$ was extracted into the TEHTDGA solution. In contrast, the spectra of the solutions containing extracted Pd(II) complexes showed a small new peak at lower wavenumber (approx. $1570 \mathrm{~cm}^{-1}$ ).

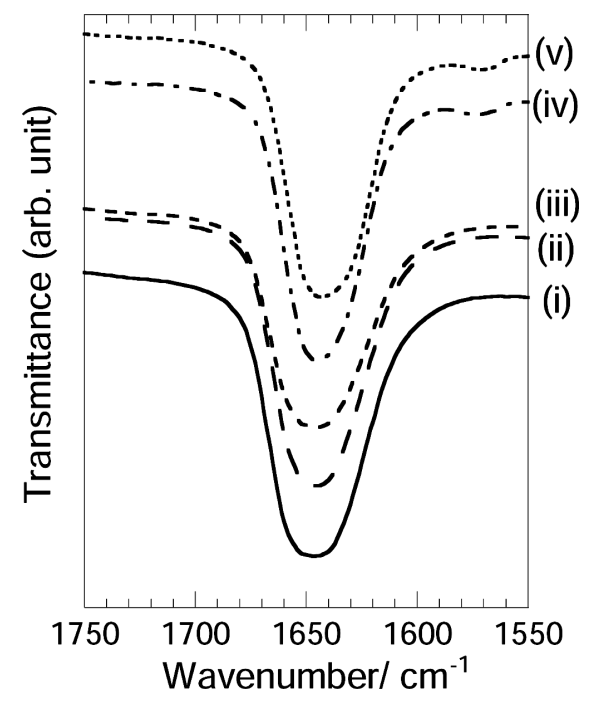

Fig. 4 Carbonyl stretching frequencies in the FT-IR spectra of TEHTDGA: (i) free, (ii) equilibrated with $\mathrm{HCl}$, (iii) equilibrated with $\mathrm{HBr}$, (iv) in complex with $\mathrm{Pd}(\mathrm{II})$ extracted from $\mathrm{HCl}$, and (v) in complex with $\mathrm{Pd}(\mathrm{II})$ extracted from $\mathrm{HBr}$. [TEHTDGA] $=0.50 \mathrm{M}$, $[\mathrm{HCl}, \mathrm{HBr}]=1.0 \mathrm{M},[\mathrm{Pd}(\mathrm{II})]$ in organic phase (iv and $\mathrm{v})=0.25 \mathrm{M}$.

Such a difference in wavenumber (approx. $75 \mathrm{~cm}^{-1}$ ) has been observed for an extractant molecule containing a free amide and the same molecule containing an amide bound to a lanthanide ion. ${ }^{16}$ However, the intensity of the new peak that we observed was too weak to be attributed to $\mathrm{Pd}(\mathrm{II})$ extraction; that is, the intensity of the $1645 \mathrm{~cm}^{-1}$ peak was approximately 80 times that of the $1570 \mathrm{~cm}^{-1}$ peak, whereas the $\operatorname{Pd}(\mathrm{II})$ concentration in the organic phase was half of the TEHTDGA concentration.

\section{Inner-sphere structure of $P d(I I)$}

To investigate the local structures of $\mathrm{Pd}(\mathrm{II})$ ions in the organic and aqueous phases, we obtained the Pd K-edge $k^{3}$-weighted EXAFS spectra and their corresponding Fourier transforms for CL-Aq, CL-Ex, BR-Aq, and BR-Ex (Fig. 5). The curve fits results are tabulated in Table 1. Because the FT-IR results indicated that the amide oxygen atom hardly coordinated to the $\mathrm{Pd}(\mathrm{II})$, the Pd-O correlation was not included in the EXAFS analyses. Speciation studies of $\mathrm{HCl}$ solutions containing $\mathrm{Pd}(\mathrm{II})^{12,17}$ have shown that $\left[\mathrm{PdCl}_{4}\right]^{2-}$ predominates at $\mathrm{HCl}$ concentrations of $\geq 1 \mathrm{M}$; therefore, the number of $\mathrm{Pd}-\mathrm{Cl}$ correlations $(N)$ was held constant at 4 , and the amplitude reduction factor $\left(S_{0}^{2}\right)$ was refined for CL-Aq. The obtained $\mathrm{Pd}-\mathrm{Cl}$ bond length $(r)$ was similar to that in the crystal structure of $\left[\mathrm{PdCl}_{4}\right]^{2-} .{ }^{13}$ The EXAFS oscillation of CL-Aq was mirrored by that of CL-Ex. First, we used the $\mathrm{Pd}-\mathrm{Cl}$ and $\mathrm{Pd}-\mathrm{S}$ correlations for CL-Ex to carry out curve fits: $N, r$, and the Debye-Waller factor squared $\left(\sigma^{2}\right)$ of $\mathrm{Pd}-\mathrm{Cl}$ were fixed at the same values as for CL-Aq. However, the difference between the obtained $r$ values for the Pd-Cl (2.31 $\AA$ ) and Pd-S (2.31 $\AA$ ) bonds of CL-Ex was smaller than the EXAFS resolution, ${ }^{18} \Delta r=\pi / 2 k_{\max }=0.12 \AA$. Therefore, we performed curve fits with one correlation, $\mathrm{Pd}-\mathrm{Cl} / \mathrm{S}$, and obtained $2.32 \AA$ for its bond length. These results mean that the $\mathrm{Pd}-\mathrm{Cl}$ bond length was similar to the $\mathrm{Pd}-\mathrm{S}$ length. Unlike in the $\mathrm{HCl}$ system, in the $\mathrm{HBr}$ system, the EXAFS oscillation for BR-Aq differed distinctly from that for BR-Ex. The structural parameter for BR-Aq was in good agreement with that for the square-planar single crystal complex, $\left[\mathrm{PdBr}_{4}\right]^{2-} .{ }^{14}$ For BR-Ex, the curve fits were carried out with the parameters for the $\mathrm{Pd}-\mathrm{Br}$ correlation obtained for BR-Aq. The $N$ value for 

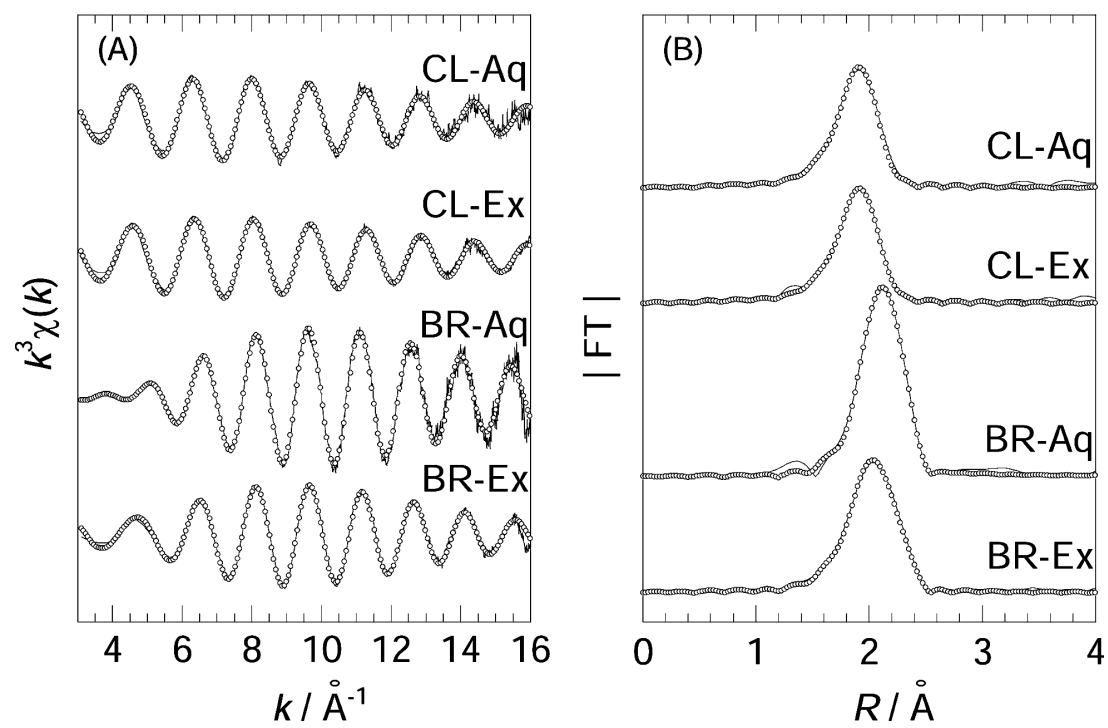

Fig. 5 (A) Pd K-edge $k^{3}$-weighted EXAFS spectra and (B) corresponding Fourier transforms. Dotted lines, theoretical fits; solid lines, experimental data. Sample designations: CL-Aq, Pd(II) in HCl; BR$\mathrm{Aq}, \mathrm{Pd}(\mathrm{II})$ in $\mathrm{HBr}$; CL-Ex, Pd(II) extracted from HCl with TEHTDGA; and BR-Ex, Pd(II) extracted with from $\mathrm{HBr}$ with TEHTDGA. [TEHTDGA $]=0.50 \mathrm{M},[\mathrm{HCl}, \mathrm{HBr}]=1.0 \mathrm{M},[\mathrm{Pd}(\mathrm{II})]=0.10 \mathrm{M}$ for all samples.

Table 1 Structural information obtained from curve fits of EXAFS $^{\mathrm{a}}$

\begin{tabular}{llllllll}
\hline & & $S_{0}{ }^{2}$ & $N$ & $r / \AA$ & $\sigma^{2} / \AA^{2}$ & $\begin{array}{c}\Delta E / \\
\mathrm{eV} \text { factor }\end{array}$ \\
\hline CL-Aq & $\mathrm{Pd}-\mathrm{Cl}$ & $0.95(6)$ & $4^{\mathrm{b}}$ & $2.31(1)$ & $0.0032(4)$ & 5.3 & 5.9 \\
$\mathrm{CL}-\mathrm{Ex}$ & $\mathrm{Pd}-\mathrm{Cl} / \mathrm{S}$ & $0.95^{\mathrm{b}}$ & $4.1(3)$ & $2.32(1)$ & $0.0031(4)$ & 5.6 & 5.0 \\
$\mathrm{BR}-\mathrm{Aq}$ & $\mathrm{Pd}-\mathrm{Br}$ & $0.95^{\mathrm{b}}$ & $4.3(4)$ & $2.45(1)$ & $0.0038(5)$ & 5.2 & 6.3 \\
$\mathrm{BR}-\mathrm{Ex}$ & $\mathrm{Pd}-\mathrm{S}$ & $0.95^{\mathrm{b}}$ & $2.3(4)$ & $2.33(1)$ & $0.0034(8)$ & 7.5 & 5.0 \\
& $\mathrm{Pd}-\mathrm{Br}$ & & $2^{\mathrm{b}}$ & $2.45^{\mathrm{b}}$ & $0.0038^{\mathrm{b}}$ & & \\
{$\left[\mathrm{PdCl}_{4}\right]^{2-\mathrm{c}}$} & $\mathrm{Pd}-\mathrm{Cl}$ & 4 & $2.295^{\mathrm{d}}$ & & & \\
{$\left[\mathrm{PdCl}_{2}(\mathrm{SR})_{2}\right]^{\mathrm{e}}$} & $\mathrm{Pd}-\mathrm{Cl}$ & 2 & $2.295^{\mathrm{d}}$ & & & \\
$\left.\mathrm{PdBr}_{4}\right]^{2-\mathrm{f}}$ & $\mathrm{Pd}-\mathrm{S}$ & $\mathrm{Pd}-\mathrm{Br}$ & 2 & $2.325^{\mathrm{d}}$ & & & \\
{$[\mathrm{P}$} & 4 & $2.444^{\mathrm{d}}$ & & & \\
\hline
\end{tabular}

a. The R-factor is given by $\left\{\sum \mid k^{3} \chi(k)\right.$ obs $-k^{3} \chi(k)$ calc $\left|\sum\right| k^{3} \chi(k)$ obs $\left.\mid\right\} \times$ 100 , estimated errors are given in parentheses, the $k$-range for Fourier transformation was $3.1-16.1 \AA^{-1}$, and the curve-fitting $R$-range was $1-3 \AA$.

b. Fixed parameter.

c. Ref. 11.

d. Average bond distance.

e. Ref. 13 ( $\mathrm{R}=p$-t-butylphenylbutyl).

f. Ref. 12.

Pd-S was approximately 2, which was consistent with the above-mentioned stoichiometry, that is, 1:2 Pd(II)/TEHTDGA.

Similar EXAFS analyses were carried out for the Pd(II) complexes extracted with DHS (Fig. S3 and Table S1, Supporting Information). The obtained $N$ and $r$ values were as follows: (1) DHS-HCl system: $N=4.1, r=2.31 \AA$ for $\mathrm{Pd}-\mathrm{Cl} / \mathrm{S}$, and (2) DHS-HBr system: $N=2.1, r=2.33 \AA$ for $\mathrm{Pd}-\mathrm{S}$, and $N=2$ (fixed), $r=2.45 \AA$ (fixed) for Pd-Br. In comparison to the TEHTDGA complexes, the Pd-S bond length in the Pd(II) complexes extracted from $\mathrm{HCl}$ or those from $\mathrm{HBr}$ was nearly the same.

In all of the systems, the inner-sphere structure of Pd(II) was similar, comprising two sulfur atoms and two halogen atoms.
This similarity is consistent with the small difference in the $E \%$ with between TEHTDGA and DHS. In contrast, the extraction efficiency decreased in the order TEHTDGA-HCl $\geq$ DHS- $\mathrm{HBr}$ $>$ DHS-HCl $>$ TEHTDGA-HBr. Remarkably, the order of the extraction efficiencies from $\mathrm{HCl}$ and $\mathrm{HBr}$ in the TEHTDGA system was the opposite of the order in the DHS system. According to HSAB theory, ${ }^{19}$ disubstituted sulfides $\left(\mathrm{R}_{2} \mathrm{~S}\right)$ and $\mathrm{Pd}(\mathrm{II})$ ion are a soft base and a soft acid, respectively, whereas, $\mathrm{Cl}^{-}$and $\mathrm{Br}^{-}$are a hard base and a border base, respectively, suggesting that the affinity of the ligands for the $\mathrm{Pd}(\mathrm{II})$ decreases in the order $\mathrm{R}_{2} \mathrm{~S}>\mathrm{Br}^{-}>\mathrm{Cl}^{-}$. This order means that the $\left[\mathrm{PdBr}_{4}\right]^{2-}$ complex is more stable than the $\left[\mathrm{PdCl}_{4}\right]^{2-}$ complex. In contrast, the $\left[\mathrm{PdBr}_{4}\right]^{2-}$ complex is more hydrophobic than the $\left[\mathrm{PdCl}_{4}\right]^{2-}$ complex. This can be beneficial for metal extraction, as mentioned in the introduction; hence, the extraction efficiency in the DHS system is probably related to the hydrophobicity of the Pd(II) complex, rather than to the substitution property of the sulfur donor atoms with the halogen atoms. The order of the extraction efficiency for the TEHTDGA system was opposite to that for the DHS system, despite the fact that the considerations discussed above for the DHS system are also applicable to the TEHTDGA system. Therefore, some other factors must be responsible for the order of the extraction efficiencies in the TEHTDGA system. Because the inner-sphere structures of $\operatorname{Pd}(\mathrm{II})$ in the two systems were nearly identical, the outer-sphere structures of $\mathrm{Pd}(\mathrm{II})$ must be considered. The amide groups of TEHTDGA were not involved in the inner-sphere coordination, suggesting that they can interact repulsively with the halogen atom in the outer-sphere of $\mathrm{Pd}(\mathrm{II})$. It can be assumed that this repulsive interaction is more significant for $\mathrm{Br}^{-}$than for $\mathrm{Cl}^{-}$ (owing to the larger size of the former), and this difference could explain the lower extraction efficiency of $\mathrm{Pd}(\mathrm{II})$ from $\mathrm{HBr}$. Elucidation of the outer-sphere interaction will require additional research, by methods such as single-crystal structural analyses. 


\section{Conclusions}

TEHTDGA extracted approximately $100 \%$ of $\mathrm{Pd}(\mathrm{II})$ from $\mathrm{HC}$ and $\mathrm{HBr}$ solutions, much faster than DHS. Measurements of the $\mathrm{Pd}(\mathrm{II})$ loading capacity indicated that the predominant complex in the organic phase was $1: 2 \mathrm{Pd}$ (II)/(TEHTDGA or DHS) in both the $\mathrm{HCl}$ system and the $\mathrm{HBr}$ system. In the TEHTDGA system, the percentage of $\mathrm{Pd}(\mathrm{II})$ extracted from $\mathrm{HBr}$ was lower than that extracted from $\mathrm{HCl}$, whereas the opposite order was observed for the DHS system. A structural study indicated that two sulfur atoms directly coordinated to the $\mathrm{Pd}(\mathrm{II})$ atom in all of the complexes, $\left[\mathrm{PdX}_{2} \mathrm{E}_{2}\right]$ (where $\mathrm{X}=\mathrm{Cl}$ or $\mathrm{Br}$ and $\mathrm{E}=$ TEHTDGA or DHS); that is, the inner-sphere structures of the DHS and TEHTDGA complexes extracted from $\mathrm{HCl}$ or $\mathrm{HBr}$ were nearly identical. These results suggest that the bulky substituents (including the amide groups) of TEHTDGA affect the extraction behavior of $\mathrm{Pd}(\mathrm{II})$.

\section{Acknowledgements}

The authors thank Ms. Hiroko Niiyama for her technical assistance. Part of this study was performed under the Shared Use Program of JAEA Facilities (proposal Nos. 2014A-E07 and 2014B-E08) supported by JAEA Advanced Characterization Nanotechnology Platform as a program of "Nanotechnology Platform" of the Ministry of Education, Culture, Sports, Science and Technology (MEXT), Japan. The synchrotron radiation experiments were performed on JAEA beamline BL11XU at SPring-8 (proposal Nos. 2014A3517 and 2014B3518).

\section{Supporting Information}

The effects of the shaking time, Pd loading capacity in the DHS system, and Pd K-edge EXAFS spectra and corresponding FTs of the DHS-Pd complexes are shown in Figs. S1-S3, respectively. The EXAFS structural parameters are given in Table S1. This material is available free of charge on the Web at http://www.jsac.or.jp/analsci/.

\section{References}

1. M. Cox, "Principles and Practices of Solvent Extraction", ed. J. Rydberg, M. Cox, C. Musikas, and G. R. Choppin, 2004, Marcel Dekker, Inc., New York, 455.

2. R. Ruhela, A. K. Singh, B. S. Tomar, and R. C. Hubli, RSC Adv., 2014, 4, 24344.

3. S. Kamata, N. Watanabe, H. Imura, and K. Ohashi, Anal. Sci., 1991, 7, 39.

4. N. Alizadeh, S. Salimi, and A. Jabbari, Anal. Sci., 2002, 18, 307.

5. S. N. Duche and P. M. Dhadke, Sep. Sci. Technol., 2002, 37, 3011 .

6. T. M. Dreher and G. P. Demopolous, Solvent Extr. Ion Exch., 1999, 17, 1231.

7. M. Mojski, Talanta, 1978, 25, 163.

8. M. Y. Mirza, Talanta, 1980, 27, 101.

9. K. Yamamoto, T. Fujibayashi, and S. Motomizu, Solvent Extr. Ion Exch., 1992, 10, 459.

10. H. Narita, M. Tanaka, K. Morisaku, and T. Abe, Chem. Lett., 2004, 33, 1144

11. H. Narita, M. Tanaka, and K. Morisaku, Miner. Eng., 2008, $21,483$.

12. H. Narita, K. Morisaku, K. Tamura, M. Tanaka, H. Shiwaku, Y. Okamoto, S. Suzuki, and T. Yaita, Ind. Eng. Chem. Res., 2014, 53, 3636.

13. R. H. B. Mais, P. G. Owston, and A. M. Wood, Acta Crystallogr., Sect. B, 1972, 28, 393.

14. D. S. Martin, Jr, J. L. Bonte, R. M. Rush, and R. A. Jacobson, Acta Crystallogr., Sect. B, 1975, 31, 2538.

15. B. Zhao, S. S. Guo, H. Z. Wang, and K. B. Yu, Chin. J. Struct. Chem., 1999, 18, 1.

16. C. Berthon and C. Chachaty, Solvent Extr. Ion Exch., 1995, 13,781

17. C. D. Tait, D. R. Janecky, and P. S. Z. Rogers, Geochim. Cosmochim. Acta, 1991, 55, 1253.

18. J. E. Penner-Hahn, Coord. Chem. Rev., 1999, 190-192, 1101.

19. G. R. Choppin, "Complexatin of Metal Ions", ed. J. Rydberg, M. Cox, C. Musikas, and G. R. Choppin, 2004, Marcel Dekker, Inc., New York, 81. 